\title{
OS EFEITOS DA QUARTA REVOLUÇÃO INDUSTRIAL NA DINÂMICA DO TRABALHO JURÍDICO
}

\author{
THE EFFECTS OF THE FOURTH INDUSTRIAL REVOLUTION ON THE \\ DYNAMICS OF LEGAL WORK
}

\author{
Fabiano Dolenc Del Masso ${ }^{\mathrm{I}}$ \\ Eduardo do Prado Godoy do Prado Godoy ${ }^{\mathrm{II}}$
}

\footnotetext{
${ }^{\mathrm{I}}$ Universidade Presbiteriana Mackenzie, São Paulo, SP, Brasil. Doutor em Direito. E-mail: dolenc@terra.com.br

II Universidade Presbiteriana Mackenzie, São Paulo, SP, Brasil. Mestrando em Direito Político e Econômico. E-mail: eduardogodoy@bb.com.br
}

Resumo: $\mathrm{O}$ artigo analisa a questáo da influência das recentes tecnologias aplicadas ao exercício das profissões jurídicas, o que se justifica para melhor compreender, em primeiro plano, no que consistem as inovaçóes na área jurídica, para depois concluir sobre seus reais avanços, benefícios ou prejuízos. A frequente criação de plataformas eletrônicas está impactando no aperfeiçoamento do exercício das profissóes jurídicas, principalmente na otimização do tempo. A partir do referencial da quarta revoluçáo industrial, o estudo trata da introdução e assimilação de novas tecnologias que podem colocar em risco a demanda direta por advogados. Nessa perspectiva, o artigo examina as empresas que oferecem produtos ou serviços inovadores por meio do uso de recursos tecnológicos para a área jurídica, as chamadas lawtechs ou legaltechs. Como metodologia, após um estudo inicial de caráter descritivo e explicativo, passa-se para um levantamento bibliográfico interdisciplinar com o objetivo de proporcionar fundamentos que induzam a concluir sobre os efeitos da quarta revolução industrial na dinâmica do trabalho jurídico. Uma das questôes para reflexão é: a figura do profissional do direito passa a ser prescindível? Nesse sentido, parece fácil concluir, que o cenário que surge aponta para uma possível redução da demanda de profissionais jurídicos a partir do estabelecimento de tais novidades tecnológicas, que já possibilitaram, inclusive, a prestação de serviços finalísticos relacionados à prática jurídica.

Palavras-chave: Quarta revolução industrial. Lawtechs. Impactos da tecnologia na dinâmica jurídica. Automaçáo na advocacia. Profissóes e tecnologia.

Abstract: The article analyzes the influence of recent technologies applied to the practice of legal professions, which is justified to better understand, in the first place, what innovations in the legal area consist of, and then to conclude on their real progress, benefits or losses. The frequent creation of electronic platforms is impacting on the improvement of the exercise of legal professions, mainly in the optimization of time. From the reference point of the fourth industrial revolution, the study deals with the introduction and

Recebido em: 16.01.2020

Aceito em: 29.07.2020 
assimilation of new technologies that may jeopardize the direct demand for lawyers. In this perspective, the article examines companies that offer innovative products or services through the use of technological resources for the legal area, the so-called lawtechs or legaltechs. As a methodology, after an initial study of a descriptive and explanatory character, we move on to an interdisciplinary bibliographic survey in order to provide foundations that lead to conclude on the effects of the fourth industrial revolution on the dynamics of legal work. One of the questions for reflection is: does the legal professional figure become expendable? In this sense, it seems easy to conclude that the scenario that emerges points to a possible reduction in the demand of legal professionals from the establishment of such technological innovations, which have already made possible the provision of finalistic services related to legal practice.

Keywords: Fourth industrial Revolution. Lawtechs. Impacts of technology in legal practice. Automation in advocacy. Professions and technolology.

\section{Introdução}

Notícias sobre as possíveis modificaçóes decorrentes da intitulada 4a revoluçáo industrial passaram a ser frequentes nos mais variados meios de comunicação, normalmente apresentando um cenário catastrófico a ser formado nos próximos anos. Agora, de forma mais cuidadosa, a academia inicia análises mais sóbrias sobre as reais consequências das aplicaçóes dos avanços tecnológicos recentemente produzidos.

De acordo com Klaus Schwab (2016, p. 12), uma evolução de ritmo exponencial e sem precedentes na história tem se materializado na quebra de paradigmas no âmbito das relaçóes sociais, abrangendo o modo como trabalhamos, nos comunicamos, nos informamos e nos divertimos, bem como a forma como a coletividade e os indivíduos organizam-se e interagem entre si, em seus múltiplos aspectos. Conforme vem sendo destacado, a sociedade passará a sofrer as consequências de uma acelerada mudança tecnológica, uma revolução digital que já se iniciou, mas que ainda não possibilitou conhecer todas as suas consequências na atual forma de viver, sobretudo, no que diz respeito ao desempenho futuro das atuais profissóes.

Segundo afirma Armin Roth (2016, p. 49), a quarta revolução industrial envolve a conectividade de todos atores humanos e mecânicos sobre a cadeia completa de valor, assim como a informatização e as análises em tempo real de todas informaçóes relevantes para esse propósito. A ideia consiste em criar processos que sejam mais eficientes e transparentes e que otimizem o valor do consumo por meio do uso de produtos e serviços inteligentes. 
Nesse cenário, não só a cultura produtiva com seus modelos operacionais e suas cadeias globais de valor tem sido radicalmente modulada pelos "novos tempos tecnológicos”, por intermédio da fusão dos domínios físico e digital, como também o espectro social das relaçóes do trabalho.

Desde as primeiras revoluçóes industriais, o principal elemento do processo produtivo - força de trabalho - passou por severas transformaçóes, tendo que se adaptar às inovaçóes tecnológicas: primeiro, ao advento da máquina a vapor; depois, ao surgimento da eletricidade; e, finalmente, a era digital da computação.

Nesse aspecto, a quarta revolução industrial não difere das demais, considerando, no entanto, que a transformação ora impingida pelas novas tecnologias, se mostra significativamente mais acentuada. A fim de ilustrar tal fato, Klaus Schwab (2016, p. 18) se vale de dados econômicos do setor automobilístico americano da década de 1990 e de empresas sediadas no vale do silício típicas da Digital Era. Segundo o autor:

Em 1990, as três maiores empresas de Detroit possuíam capitalização de mercado combinada de US\$ 36 bilhóes, faturamento de US\$ 250 bilhóes, e 1,2 milhão de empregados. Em 2014, as três maiores empresas do vale do silício tinham uma capitalização de mercado consideravelmente mais elevada (US\$ 1,09 trilhão), haviam gerado aproximadamente as mesmas receitas (US\$ 247 bilhóes), mas com cerca de 10 vezes menos empregados (137 mil).

A substituição do trabalho por capital parece decorrer como uma consequência natural do processo evolucionário, o que implica cada vez mais na diminuição do percentual da máo-de-obra no PIB dos países desenvolvidos ou em desenvolvimento (SCHWAB, 2016, p. 20). A lógica desse processo é simples: o progresso das inovaçóes tecnológicas propicia a reduçáo do custo dos bens de investimento, que, por sua vez, favorece o aumento do capital em detrimento da força de trabalho humana.

Nesse sentido, Carl Benedikt Frey e Michael A. Osborne (2013) afirmam que o declínio dos preços relacionados aos custos dos computadores criou vastos incentivos econômicos para que empregadores substituam trabalhadores por aquilo que eles denominam de computer capital, ou seja, a cumulação de computadores aos equipamentos ligados ao controle dessas máquinas.

De fato, o avanço tecnológico característico da quarta revolução industrial, consubstanciado nas inovaçóes da computação, da nanotecnologia, da impressão $3 \mathrm{D}$, da genética e da robótica estão mudando radicalmente o panorama do mercado de trabalho (EBERHARD, 2017, p. 47) .

Um estudo realizado em 2013 por pesquisadores da Universidade de Oxford (FREY; OSBORNE, 2013), acerca de quão suscetíveis à informatização são os empregos, aponta que por volta de 2033, 47\% dos empregos em economias desenvolvidas terão alto risco de serem automatizados. 
Nos tempos remotos da computação, durante o advento da terceira revolução industrial, a informatizaçăo servia unicamente ao propósito de prestar suporte às tarefas rotineiras baseadas em regras sedimentadas. No entanto, o avanço da informatização e o desenvolvimento de novos algoritmos têm possibilitado à inteligência artificial explorar domínios dependentes de padróes de reconhecimento nunca desvendados artificialmente, possibilitando, desse modo, a substituição da força de trabalho humana também em um grande campo de tarefas não rotineiras (FREY; OSBORNE, 2013).

De acordo com uma análise realizada recentemente (JESUTHASAN, 2017, p. 9), os custos economizados por um processo de automaçáo cognitiva representariam $60 \%$ a $80 \%$ dos custos ordinários com trabalhadores tradicionais, em franca vantagem se comparados a um processo de terceirização da força de trabalho, que resultaria em uma economia em torno de $25 \%$ a $30 \%$.

Como decorrência dessa realidade imposta pela evolução digital, instituiçôes educacionais estão sendo demandadas a reagirem e a ajustarem a formação dos novos estudantes aos futuros desafios que estáo sendo e que seráo impostos, por intermédio da identificação de novos perfis de trabalho e de um processo de desenvolvimento das habilidades necessárias ao desempenho das tarefas relacionadas às vindouras profissōes (EBERHARD, 2017, p. 48).

Todas essas mudanças e transformaçōes se inserem no contexto da chamada "Indústria 4.0", termo cunhado originalmente pelo governo alemão, no ano de 2013, para assegurar competitividade no âmbito da produçáo local de manufaturas de alta tecnologia. Atualmente, o termo transcende sua idealização inicial, representando uma iniciativa para melhorar a produtividade e a eficiência de toda a cadeia de valor em geral (EBERHARD' 2017. p. 48).

A nova era industrial apresenta ao mundo tendências consubstanciadas na entrega de produtos cada vez mais customizados e flexíveis, com fluxo de produção modular em uma economia ótima, que priorize interação, domínio da tecnologia e eficiência operacional (HWANG, 2016, p. 12-13).

\section{Dinâmica de trabalho dos profissionais do Direito}

O plano jurídico e a respectiva dinâmica de trabalho de profissionais da área do direito, que, até entáo, encontravam-se relativamente a parte dos efeitos dessa revolução digital, passam, de forma progressiva, a serem afetados pelas tecnologias características dessa nova era. Já existem ferramentas capazes de automatizar tarefas atribuídas a advogados, economizando o tempo despendido por profissionais da área nessas atribuiçóes rotineiras da advocacia. 
A projeção geralmente realizada pelos experts em tecnologia, aponta que cerca de quase $1 / 4$ do trabalho de um advogado seria passível de automaçáo. Nesse panorama, grandes escritórios de advocacia norte-americanos têm investido em start-ups cujo escopo consiste em explorar tecnologias aplicáveis à área do direito. Parte deles acredita que as inovações e transformações disruptivas, tão mencionadas em outras áreas e segmentos, enfim chegaram ao campo jurídico.

Adentrando no panorama da inteligência artificial voltada à prática jurídica, a empresa IBM avançou no desenvolvimento de uma ferramenta capaz de auxiliar advogados em tarefas não só rotineiras. Trata-se do programa "Ross Intelligence", que utiliza a tecnologia de inteligência artificial da plataforma cognitiva "Watson”.

A associação de computadores dotados de processadores mais rápidos, potentes e menores a algoritmos estatísticos, ao reconhecimento da linguagem humana e à interpretação semântica de textos promete revolucionar a forma como atuam os operadores da área do direito. Compreender melhor no que consistem as inovações na área jurídica, suas origens, seus avanços, benefícios ou prejuízos gerados e as expectativas em relação a esse processo evolucionário perfazem o propósito do presente trabalho acadêmico.

\subsection{Avanços tecnológicos e suas aplicaçóes na área jurídica}

Ao se examinar a evolução da prática jurídica, é possível observar que a interação entre direito e tecnologia, assim como em outras áreas do saber humano, segue em rápida expansão. Não é preciso nenhum esforço cognitivo para tal constatação. Basta pensar na árdua tarefa de peticionamento manuscrito, depois por meio de máquinas de escrever, até o advento da era da computação. A busca por excertos jurisprudenciais em meio a milhares de fascículos da Revista dos Tribunais (RT) também se revela mais tortuosa e morosa se comparada às modernas ferramentas de busca de jurisprudência. De igual modo, atualmente, afigura-se inimaginável uma busca manual de publicaçóes no Diário Oficial da União. E o que dizer das infindáveis filas necessárias para uma simples consulta processual, diante dos atuais processos judiciais eletrônicos, que oferecem a comodidade de consulta a detalhes do processo sem que o advogado precise deixar seu escritório?

As profissões jurídicas e os instrumentos para o seu eficiente exercício têm sido alvo das inovações tecnológicas. Desde o advento da quarta revolução industrial, no entanto, o ritmo de inserção de novidades tecnológicas no plano jurídico, acompanhando a tendência de outros segmentos, tem adquirido contornos de progressóes muito mais frequentes do que se imaginava.

O desenvolvimento de sistemas jurídicos, esses entendidos não sob o viés característico da disciplina acadêmica ou do ordenamento jurídico, mas sim pela sua concepção desenvolvida no plano tecnológico, trouxe aos operadores do direito inúmeros facilitadores, dentre os quais se destacam os softwares jurídicos para a gestáo de processos, 
gestão de documentos, controle de prazos, organização da rotina e produtividade, atendimento a clientes, gestão de equipes e gestão financeira.

Inúmeros softwares jurídicos à disposição no mercado possibilitam ao profissional da área otimizar a dinâmica de um escritório, viabilizando: o cadastramento de processos em lotes por meio de um procedimento simplificado após a mera impostação do número da inscrição da $\mathrm{OAB}$, o recebimento de atualizaçóes processuais automáticas provenientes diretamente dos sites dos Tribunais nos quais tramitam os processos, dentre outras facilidades relacionadas à gestão processual, dispensando-se, assim, controles manuais em planilhas de Excel, por exemplo.

Em termos de gestão de documentos, os atuais sistemas possibilitam não só a organização de dados e documentos relativos a um processo ou cliente, como também a confecção de peças padronizadas, que serão concluídas após a mera inserção de dados dos clientes em uma plataforma específica, otimizando a rotina de escritórios que trabalham com contencioso massificado.

Sistemas de controle de prazos, que atualmente são oferecidos a advogados já possibilitam o acompanhamento de todos os compromissos processuais e administrativos de todo o escritório, oferecendo uma visão gerencial ampla. A exemplo de um gerenciador de tarefas, os sistemas da espécie possibilitam plena ciência de quando os procedimentos necessários ao cumprimento de determinado prazo devem ser iniciados, oportunizando ao gestor, ainda, intervir nas situaçóes em que identifique desalinhamento entre o progresso da tarefa executada e o prazo remanescente para a conclusáo dos trabalhos. Adicionalmente, há a possibilidade de se classificar informaçóes, restringindo o acesso àquelas tidas por sensíveis.

No que tange à organização da rotina e produtividade, os gerenciadores desenvolvidos especificamente para quem atua na área do direito viabilizam a ordenação de tarefas diárias típicas de um escritório de advocacia, a exemplo de reunióes com clientes, audiências, acompanhamento de perícias, além de possibilitarem a delegação de atividades por meio do próprio sistema, acessível de qualquer plataforma com acesso à internet ou por meio de aplicativos para celular.

Por meio dessas inovações tecnológicas naárea jurídica, até mesmo o relacionamento com o cliente pode passar a ser desenvolvido de forma automatizada. Sem prejuízo das costumeiras reunióes presenciais, quando julgadas necessárias, o advogado moderno que conta com uma carteira relativamente extensa de clientes pode intensificar e personalizar o relacionamento com sua clientela, mitigando insatisfaçóes corriqueiras, por meio de softwares que armazenem a maior quantidade de dados possíveis do representado, acessíveis de qualquer lugar, e por meio de uma rotina de follow up, que pode ir desde uma felicitação ao cliente em seu aniversário até a geração de relatórios personalizados e links para acesso aos últimos andamentos processuais. 
A gestão de equipes jurídicas em tempos atuais também se mostra inserida no contexto tecnológico. Delegar tarefas, acompanhar seu desenvolvimento ou eventuais atrasos podem ser realizados por tais plataformas jurídicas, com o auxílio de notificaçóes automatizadas via e-mail ou mensagens de texto via celular.

Ao mesmo tempo em que esses softwares jurídicos facilitam a administração dos aspectos jurídicos de uma rotina dos profissionais da área e de aspectos relacionados à gestão de clientes e equipes, eles também podem auxiliar na gestão financeira da sociedade jurídica, abrangendo serviços relacionados a controle de fluxo de caixa, emissão de faturas comerciais, confecção de relatórios gerenciais, dentre outros.

O profissional jurídico contemporâneo conta com uma série de ferramentas tecnológicas desenvolvidas, a partir de uma única plataforma eletrônica de serviços, para o fim de aperfeiçoar a utilização de seu tempo de trabalho.

\subsection{Criação das lawtechs}

No entanto, as inovaçóes tecnológicas na área jurídica não se limitam às ferramentas facilitadoras de tarefas rotineiras e repetitivas, voltadas à gestão de um escritório ou de um departamento jurídico. Os avanços vão além. E isso porque se encontra em curso uma verdadeira mudança cultural, que não é exclusiva dos profissionais da área jurídica.

De acordo com uma pesquisa realizada por respeitáveis organizaçóes, tais como Cisco, Pew Research, Time, Bentley University e Delloite (EBERHARD'2017. p. 48), a geração millenium, também conhecida como geração "Y” (nascidos entre 1980 e 1990), juntamente com a geração " $Z$ ” (nascidos entre 1990 até 2010), crescidos no universo das novas tecnologias, representarão, em 2020, metade da força de trabalho. Essas geraçóes apresentam mudanças significativas em relação às que as antecederam, sobretudo no que tange à concepção que formulam acerca do ambiente e das relaçóes de trabalho. Segundo apurado na pesquisa:

The majority believes that office attendance is unnecessary on a regular basis, only $20 \%$ think that they can trust their leaders and $40 \%$ say that they should be promoted at least every second year. Furthermore, $84 \%$ of millennials say that making a difference in the world is very important for them and $92 \%$ think that businesses should be measured by more than profits. Besides, millennials will more likely change their employers several times and engage in a lifelong learning in order to fulfill future job requirements. Most millennials are presumed to embrace an intrapreneurial style of work. Intrapreneurs prefer a workplace supporting creativity and autonomy. Additionally, intrapreneurs are usually highly selfmotivated, proactive and action-oriented people who are comfortable with taking the initiative, even within the boundaries of an organization. Intrapreneurs are presumed to play a major role in the future success of companies` (Investopia, 2016) (EBERHARD' 2017. p. 48)

Essa quebra de paradigma na dinâmica das relações de trabalho tem favorecido a introdução e assimilação de novas tecnologias, sobretudo na dinâmica do trabalho 
jurídico. Exemplo disso é o considerável número de empresas que oferecem produtos ou serviços inovadores por meio do uso de recursos tecnológicos para a área jurídica no Brasil, as chamadas lawtechs ou legaltechs.

Associado a esse processo de transformação cultural, o fato de o Brasil ser um país com alto índice de judicialização de demandas, sobretudo se comparado a países desenvolvidos, e, portanto, um ambiente amplamente propício e fértil para o desenvolvimento de tecnologias na área, tem contribuído para que o país desempenhe um papel vanguardista na dinâmica da revolução digital no panorama jurídico.

Nesse contexto, em 2017, foi constituída a Associação Brasileira de Lawtechs e Legaltechs - AB2L, uma associação cujo propósito consiste em contribuir para: (i) o desenvolvimento de um ambiente de tecnologia e inovação na prática jurídica; (ii) a implementação e o aprimoramento da legislação, bem como a atuação junto à Administração Pública, de modo a fomentar inovações na área; (iii) o desenvolvimento de estudos e pesquisas, tanto para a informação da sociedade quanto para a qualificação dos profissionais interessados; e (iv) a integração entre profissionais das áreas jurídica e tecnológica, de modo a criar um ecossistema de inovação ${ }^{1}$.

A AB2L, segundo seu fundador e presidente, Bruno Feigelson, nasceu da identificação da necessidade de se reunir, em um foro comum, empresas dispostas a pensar principalmente sobre o futuro da advocacia e sobre a perspectiva de atuaçáo do que se denominou "Advogado 2.0". Explorar as inovaçôes tecnológicas já geradas, integrar soluções, contribuir com a iniciativa educacional e auxiliar na construção de marcos regulatórios foram alguns dos motivadores para a criação da associação ${ }^{2}$.

Pela análise dos dados da associação, constata-se que, de outubro de 2017, mês em que foi publicado o primeiro quadro de start-ups jurídicas associadas à $\mathrm{AB} 2 \mathrm{~L}$, a março de 2018, quando foi publicada a atualizaçáo do radar de empresas associadas, houve um aumento aproximado de $108 \%$ de legaltechs no período, passando de 51 para 106, em apenas cinco meses. Esses números confirmam o ritmo acelerado do crescimento de empresas dispostas a apresentar inovaçóes tecnológicas no setor jurídico.

Atualmente, as lawtechs são agrupadas em nove categorias (conforme radar de empresas associadas, em 27.03.2018) ${ }^{3}$ pela AB2L: (i) Analytics e Jurimetria - 12 empresas; (ii) Automação e Gestão de Documentos - 8 empresas; (iii) Conteúdo Jurídico, Educação e Consultoria - 11 empresas; (iv) Extração e Monitoramento de dados públicos - 18 empresas; (v) Gestão de Escritórios e Departamentos Jurídicos - 21 empresas; (vi) Inteligência Artificial - Setor público - 1 empresa; (vii) Rede de Profissionais - 16

1 Disponível em https://www.ab2l.org.br/missao-e-objetivos. Acesso em abril/2018.

2 Disponível em https:/www.aurum.com.br/blog/advocacia-2-0-bruno-feigelson-aurum-summit-2017/\#otua. Acesso em abril/2018.

3 Disponível em https://www.ab2l.org.br/radar Acesso em abril/2018. 
empresas; (viii) Resolução de Conflitos On-Line - 17 empresas; e (ix) Faça você mesmo -2 empresas.

Nos Estados Unidos, segundo levantamento do website Codex da Universidade de Stanford ${ }^{4}$, foram listadas 843 start-ups jurídicas na área de tecnologia, distribuídas também em nove categorias: (i) marketplace, (ii) document automation, (iii) pratice management, (iv) legal research, (v) legal education, (vi) online dispute resolution, (vii) E-Discovery, (viii) Analytics e (ix) compliance.

Nesse universo de empresas, algumas foram pioneiras no Brasil e dada sua elevada difusão, já fazem parte da rotina de trabalho de muitos profissionais do direito. É o caso, por exemplo, das plataformas "Jusbrasil"5, "JOTA"6, "Digesto"7 "Escavador"8 e "Jurídico Certo"'.

Outras plataformas apresentam propostas inovadoras, que aplicam à prática jurídica a combinação da inteligência artificial (IA) e do aprendizado automatizado ou aprendizado de máquina (learning machine). É o caso, por exemplo, das start-ups que integram a categoria de "analytics e jurimetria".

Nesse campo, atua a "GetJus", uma empresa goiana, cujo propósito consiste em analisar e verificar riscos tributários na emissão de notas fiscais eletrônicas (NF-e), por meio da utilização de algoritmos. Sua aplicação permite a aferição de alíquotas e bases de cálculos da incidência de tributos sobre a produção e circulação de bens. Além disso, o programa também permite o monitoramento a identificação de possíveis erros na emissão de conhecimento de transporte eletrônico (CTe) e no manifesto de documentos fiscais eletrônicos (MDF-e), documentos necessários ao transporte de $\operatorname{cargas}^{10}$.

Ainda no campo da jurimetria, algumas empresas, como a "Jurimetric", têm trabalhado para oferecer aos profissionais do direito a possibilidade de realizaçáo de prediçóes e análise de informaçóes relevantes em variados ramos do direito, por meio de métodos quantitativos e estatísticos voltados a área, de modo a auxiliar o advogado a definir a estratégia jurídica em face, por exemplo, da taxa de procedência ou improcedência

4 Disponível em https://techindex.law.stanford.edu. Acesso em abril de 2018.

5 Lawtech inserida na categoria "rede de profissionais", cujo propósito consiste em conectar advogados a pessoas que necessitem de serviços jurídicos. Disponível em https://www.jusbrasil.com.br

6 Lawtech inserida na categoria "conteúdo jurídico, educação e consultoria", cujo propósito consiste em ofertar a operadores do direito ou náo notícias especializadas do mundo jurídico, inclusive por meio de relatórios customizados às áreas de atuação do profissional ou de interesse. Disponível em https://www.jota.info

7 Lawtech inserida na categoria "analytics e jurimetria", cujo propósito consiste em oferecer a profissionais da área do direito assessoria para a compreensão de quantidades massivas de dados, para viabilizar a tomada de melhores decisões. Disponível em https://www.digesto.com.br

8 Lawtech inserida na categoria "monitoramento e extração de dados públicos", cujo propósito consiste no o monitoramento de publicaçóes em diários oficiais e no oferecimento uma base de dados de profissionais da área do direito. Disponível em https://www.escavador.com

9 Lawtech inserida na categoria "rede de profissionais", cujo propósito consiste em conectar advogados a pessoas que necessitem de serviços jurídicos, inclusive correspondentes jurídicos. Disponível em https://juridicocerto. com

10 Disponível em https://www.getjus.com.br. Acesso em abril de 2018. 
de uma ação, do valor médio de indenização para determinado tipo de ação, do tempo médio de duração de um processo em determinado juízo ${ }^{11}$. Nesse caso, a compilação e estruturação de informações pode auxiliar o profissional na definição da melhor estratégia processual em face do caso concreto.

Como forma de melhorar os índices de provisionamento de demandas jurídicas, algumas empresas e departamentos jurídicos podem contar atualmente com uma ferramenta específica para o controle de baixa de processos, por meio de algoritmos que identificam evidências de baixa, prevenindo o dispêndio de recursos e tempo com demandas extintas. Tal solução tecnológica é oferecida, por exemplo, pela start-up "Kurier", por meio do software "Kurier baixa" 12 .

Ainda nessa linha de analytics, a legaltech "Semantix" oferece soluçôes tecnológicas capazes de trabalhar dados brutos de fontes diversas (correlação de dados), identificando padrôes e extraindo informaçóes úteis aos seus usuários. No caso de processos trabalhistas, sáo colhidas informaçóes de dados do RH e de políticas internas da empresa, do IBGE, de dados cadastrais, de órgãos de proteção ao crédito e de redes sociais; já nos processos cíveis, a obtenção de dados advém de informaçôes relativas a produtos e serviços, de serviços de atendimento ao consumidor, de ouvidorias, do Procon, de sites de resolução de conflitos ("reclame aqui"), e também de redes sociais.

Por meio dessa sistemática, o software desenvolvido pela empresa, com amparo na inteligência artificial, é capaz de indicar a propensão ao ajuizamento de demandas e a realizaçáo de acordos, estabelecendo parâmetros a política de acordos, com base no perfil do requerente, nas características do processo e nos padróes dos tribunais ${ }^{13}$.

No cenário internacional, a plataforma "Luminance"14, derivada dos avanços de learning machine da Universidade de Cambridge, apresenta ferramentas avançadas para a realizaçáo de processos de due diligence ou compliance empresarial. O escopo dos serviços oferecidos pela ferramenta é de fato surpreendente e pode tornar a árdua tarefa de análise de contratos e dados empresarias mais célere e segura. Sua plataforma de inteligência artificial é capaz de ler e entender, por contexto e conteúdo, qualquer espécie de documento, em qualquer idioma, encontrando informaçóes significantes e anomalias sem a necessidade de customização ou configuração prévia.

Desse modo, por meio de algoritmos de reconhecimento padronizados, análises de probabilidades estatísticas avançadas e do aprendizado de máquina supervisionado e não supervisionado, o próprio programa é capaz de identificar cláusulas não usuais, termos faltantes ou inconsistentes e indicar os respectivos riscos.

11 Disponível em http://www.jurimetric.com.br. Acesso em abril de 2018.

12 Disponível em http://kuriertecnologia.com.br/kurier-baixa. Acesso em abril de 2018.

13 Disponível em http://www.semantix.com.br/semantix-aijus. Acesso em abril de 2018.

14 Disponível em https://www.luminance.com. Acesso em abril de 2018. 
Ferramentas similares (GREENE, 2016) em termos de leitura e compreensão semântica de textos jurídicos já viabilizam a tradução de termos técnico-jurídicos para uma linguagem mais acessível a pessoas não familiarizadas à dinâmica contratual. Um algoritmo analisa o texto e procura por inconsistências lógicas, termos definidos e não utilizados e expressóes passíveis de simplificação ou que possam ser substituídas por outras menos ambíguas.

Em adição, essas novas ferramentas são capazes de, a partir do upload de uma foto do documento ou do arquivo em um aplicativo de celular, destacar direitos e privilégios contidos no contrato e desmascarar previsóes contratuais escondidas em seçóes desorganizadas.

Outra tecnologia desenvolvida pela start-up jurídica "ClearstoneIP", auxilia as empresas a evitarem a violação de patentes quando do lançamento de seus produtos. Em vez do trabalho de um advogado, que poderia durar semanas de busca em décadas de registros de patentes, a plataforma chamada "Element" pode desempenhar a mesma tarefa em apenas 30 ou 40 minutos, indicando conceitos contidos nas patentes que sejam passíveis de infração (GREENE, 2016).

Talvez a plataforma mais famosa já desenvolvida no âmbito da automação das atividades jurídicas até o momento seja o Ross Intelligence, criado pela IBM a partir do sistema cognitivo Watson.

O supercomputador Watson já vinha sendo utilizado de forma exitosa e revolucionária na área da medicina, recomendando, em poucos minutos, tratamentos personalizados para pacientes com câncer, mediante a comparação de históricos da doença e dos tratamentos, exames e dados genéticos, com um vasto universo de conhecimentos médicos atualizados (CHA, 2016).

Para se ter ideia da capacidade do banco de dados que serve de suporte a essa ferramenta tecnológica, o sistema conta com o conhecimento de 600 mil reportes de evidências médicas, 1,5 milhôes de registros de pacientes e testes clínicos, além de 2 milhôes de páginas de textos de periódicos jornalísticos médicos, para a realização de comparaçóes, com o propósito final de reconhecimento de padróes (COHN, 2013, p. 17).

No que tange ao Ross, a variável jurídica do Watson, cuida-se de um avançado sistema de inteligência artificial, composto integralmente de big data, capaz de ler e compreender a linguagem natural, postular hipóteses, pesquisar e apresentar respostas conclusivas amparadas em referências e citações. Seu sistema de learning machine lhe permite o aprendizado automático a partir de sua experiência e da interação com os usuários, resultando em respostas cada vez mais céleres e precisas ${ }^{15}$. Atualmente, a

15 Disponível em https://rossintelligence.com. Acesso em abril de 2018. 
plataforma Ross oferece consultoria jurídica em três áreas: falência, propriedade intelectual e direito do trabalho ${ }^{16}$.

As inovaçóes tecnológicas têm sido igualmente manejadas com o propósito de conciliação, mediação e arbitragem, contribuindo, desse modo, para a política de desjudicialização de demandas há tempo perseguida pelo Poder Judiciário. Plataformas de resoluçáo de conflitos on-line, as chamadas "ODR" - Online Dispute Resolutions, tais como: a "Sem Processo", a "Concilie", a "Justto", a "Itkos", a "Find Resolution", a "Acordo Fechado", dentre tantas outras, vêm se valendo da criatividade e inovação para transformar o cenário de litígio.

No caso da plataforma Sem Processo ${ }^{17}$, por exemplo, oportuniza-se a advogados de demandantes contatarem advogados dos demandados, com auxílio do provedor de serviços, e a estabelecerem toda a cadeia de tratativas até o upload da minuta final de acordo em um ambiente de chat, sem custos à parte demandante.

Já o Justto ${ }^{18}$, valendo-se de um procedimento de automação de acordos e de duas plataformas (Abitranet e Acordo Fácil), oferece: estratégias de especialistas em negociação, possibilidade de negociaçóes em lotes, minutas pré-customizadas e assinaturas eletrônicas, que dispensam a presença física dos envolvidos, além de relatórios analíticos sobre os acordos para fins de prestação de contas a clientes.

A plataforma Abitranet da start-up Justto, primeira câmara de arbitragem no ambiente on-line, possibilita, ainda, o acesso das partes a um processo de resolução de conflitos rápido, seguro e com valores pré-determinados e acessíveis, em contraste com os altos custos inerentes a um processo de arbitragem convencional.

Em termos de mediação e conciliação, a Itkos também se vale do ambiente on-line para possibilitar a instauraçáo de processos de resoluçáo de conflitos de forma independente da presença física das partes, o que contribui para a celeridade da solução dos litígios ${ }^{19}$.

Empresas norte-americanas, como a Arbi Claims, de igual modo, se inserem nesse mercado de lawtechs vocacionadas à resoluçáo de conflitos. Mediante o pagamento de preços modestos, as partes concordam em se submeter a um julgamento arbitrado por um advogado disponibilizado pela empresa (GREENE, 2016)

Dentre as inovaçóes disruptivas no panorama legal, há, ainda, as legaltechs direcionadas não exclusivamente àqueles que se enquadram como operadores do direito, mas também aos que apenas se utilizam dos serviços jurídicos. Nesse contexto, start-ups especializadas em promover tarefas até entáo desempenhadas por meio de consultoria

16 Idem.

17 Disponível em https://www.semprocesso.com.br. Acesso em abril de 2018.

18 Disponível em https://justto.com.br. Acesso em abril de 2018.

19 Disponível em http://www.itkos.com.br. Acesso em abril de 2018. 
jurídica vêm ganhando espaço. É o caso da "Como Registrar" e da "Juridoc". A plataforma pernambucana de registro de marcas funciona como uma espécie de intermediadora na realização de serviços junto ao Instituto Nacional de Propriedade Intelectual e permite ao usuário que, com passos simplificados e por meio de um ambiente on-line, promova o início do processo de registro de sua marca ${ }^{20}$.

Atuando de forma mais ampla, a legaltech Juridcoc ${ }^{21}$ oferece a seus usuários serviços que váo desde a abertura de uma empresa a registros de marcas e à elaboração de documentos e contratos jurídicos personalizados. Pela proposta da start-up, bastaria ao interessado imputar os dados cadastrais em sua plataforma on-line, para ter acesso, em poucos minutos, a minutas finalizadas dos mais variados contratos, incluindo contratos de prestação de serviços, termos de confidencialidade, contratos de trabalho etc.

Embora essa legaltech ressalve não ser um escritório de advocacia, tampouco substituir o acompanhamento profissional de um advogado, resta claro que seu propósito é conferir autonomia jurídica àqueles que demandam serviços jurídicos.

Serviço similar é prestado pela start-up Looplex ${ }^{22}$, que a partir de um procedimento simplificado de perguntas e respostas e por meio de uma plataforma guiada por inteligência artificial, são gerados documentos de natureza jurídica, passíveis de customização formais, que podem se integrar a outros sistemas jurídicos de gestáo de processos.

O sistema desenvolvido pela Looplex utiliza também um mecanismo de tradução inteligente, por meio do qual documentos de alta complexidade são traduzidos e contextualizados a um vocabulário jurídico.

Ainda no campo de serviços jurídicos voltados a clientes finais, a start-up alemã "Frag-einen-anwalt" oferece aconselhamento legal (GREENE, 2016), por meio de advogados on-line, em menos de 40 minutos. As respostas dadas aos clientes são postadas de modo que visitantes possam ter acesso a ela e possam verificar se lhe são úteis, independentemente do pagamento de taxas por tal conferência.

Aspecto que chama a atenção em legaltechs voltadas ao atendimento a clientes é o fato de, em muitos dos serviços ofertados, ser dispensável a atuação direta de um profissional da área jurídica. Conquanto a formulação e o desenvolvimento dos sistemas de algoritmos presentes na inteligência artificial utilizada em tais plataformas demandem a participação de um expert jurídico, após a finalização da modelagem do produto, a figura do profissional do direito passa a ser prescindível.

Diferentemente de outras ferramentas desenvolvidas para atuarem como "meio" para o exercício da advocacia, tais instrumentos tecnológicos cumprem, ao menos em parte, a função finalística da atuação jurídica.

20 Disponível em https://www.comoregistrar.com.br. Acesso em abril de 2018.

21 Disponível em https://www.juridoc.com.br. Acesso em abril de 2018.

22 Disponível em http://www.looplex.com.br. Acesso em abril de 2018. 
Nesse sentido, nos parece fácil concluir, que o cenário que surge aponta para uma possível redução da demanda de profissionais jurídicos a partir do estabelecimento de tais novidades tecnológicas.

\subsection{Sistema de trabalho coworking}

De fato, a dinâmica de trabalho do novo advogado tem sido alvo de sensíveis transformaçóes disruptivas, sobretudo se examinados os novos ambientes de trabalho. Seguindo uma tendência própria de start-ups e de empresas relacionadas à tecnologia, muitos profissionais do direito, em especial novos advogados pertencentes à geraçáo millenium e em início de carreira, têm se valido de sistemas de trabalho na modalidade de coworking.

Por meio de tal sistema, o profissional exerce sua atividade laborativa em um espaço físico integrado, voltado ao trabalho colaborativo. Um ambiente único, caracterizado pela flexibilidade e típico de profissionais autônomos que podem pertencer a áreas diversas ${ }^{23}$.

No sistema de coworking, advogados podem compartilhar o mesmo ambiente de trabalho com freelancers e demais profissionais liberais, em substituição ao sistema ortodoxo de salas comerciais únicas para escritórios de advocacia. Cogitar algo da espécie há duas décadas seria algo impensável para atuantes da área, em especial por decorrência da glamorizaçáo de que sempre foi alvo a carreira jurídica.

Algo similar também tem sido adotado por advogados indispostos a enfrentar jornadas exaustivas que beiram cem horas semanais. Para tais profissionais, a adesão a um sistema de "advogado-por-demanda" com trabalho home-office passa a ser uma opção, a exemplo do que ocorre com aqueles que trabalham para a legaltech "Hire an Esquire". Nessa start-up jurídica, os profissionais cadastrados, que já somam em torno de cinco mil, são demandados pontualmente por consumidores que necessitem ajuda legal ou por firmas que necessitem de atuação de casos específicos (GREENE, 2016).

Como se vê, o universo jurídico vem sendo modulado a cada dia pelas inovações tecnológicas características da quarta revolução industrial.

\section{Contribuiçáo institucional do poder público}

Outro fator que tem impulsionado o avanço tecnológico na área jurídica é a iniciativa do Poder Público de também avançar institucionalmente no campo das inovaçóes tecnológicas, por meio, v.g., da implementação de processos judiciais e peticionamento eletrônicos.

23 Disponível em https://coworkingbrasil.org. Acesso em abril de 2018. 
A implantação de processos judiciais eletrônicos no âmbito do Poder Judiciário brasileiro se tornou possível a partir da Lei n. ${ }^{\circ}$ 11.419/2006 ${ }^{24}$ e da Medida Provisória 2.200-2/2001, que instituiu a Infraestrutura de Chaves Públicas, conferindo a segurança necessária para o desenvolvimento da tecnologia.

De acordo com um estudo promovido pelo Conselho Nacional de Justiça ${ }^{25}$, em 2015 havia cerca de quatro milhóes de processos judiciais eletrônicos em trâmite em pelo menos 2.200 órgãos julgadores. No ano de 2017, esse número já havia saltado para 15,7 milhóes de demandas pela via eletrônica ${ }^{26}$. A versão eletrônica dos processos judicias tem contribuído para a materialização dos princípios da celeridade e da razoável duração do processo, trazidos ao ordenamento constitucional pela Emenda n. ${ }^{\circ}$ 45/2004, na medida em que ela assegura o rápido trâmite processual no âmbito dos cartórios. Pelos dados coletados com a pesquisa, processos judiciais físicos apresentam uma média de 144,19 dias no tempo cartorial, enquanto que os processos eletrônicos apresentam uma média de 97,36 dias, o que indica uma redução de 48\% do tempo de trâmite dos processos eletrônicos.

Outra vantagem constatada consiste na redução do prazo de julgamento das demandas. Segundo apurado pelo aludido estudo do CNJ, juízes decidem mais rapidamente os processos judiciais eletrônicos do que os processos físicos, o que faz com que os processos eletrônicos acabem sendo mais céleres.

Tais dados ilustram e reforçam o fato de como os reflexos da quarta revolução industrial, cada vez mais têm impactado o universo jurídico, gerando ganhos de eficiência e produtividade.

\section{Reflexos no mercado do trabalho}

Conquanto se evidenciem aspectos positivos desse processo evolucionário tecnológico, pontos aparentemente negativos também exsurgem dessa hodierna realidade.

Em sua referida obra acerca da quarta revolução industrial, Klaus Schwab (2016, p. 43) trata dos impactos da revoluçáo digital sobre o mercado de trabalho e sobre o nível de emprego. Segundo apurado em sua pesquisa, "os primeiros sinais apontam para uma onda de inovaçóes que substituirão o trabalho de vários setores e categorias de trabalho que, provavelmente, irão ocorrer nas próximas décadas”.

24 Lei que dispôs sobre a informatização do processo judicial e alterou o Código de Processo Civil.

25 Conforme sumário executivo produzido pelo CNJ: "Justiça Pesquisa, Políticas Públicas do Poder Judiciário: Uma análise quantitativa e qualitativa do impacto da implantação do processo judicial eletrônico (PJe) na produtividade dos Tribunais". Disponível em http://www.cnj.jus.br/files/conteudo/ arquivo/2018/02/8fca1c5a0d1bac23a1d549c6f590cfce.pdf. Acesso em abril de 2018.

26 Disponível em http://www.cnj.jus.br/noticias/cnj/85273-processo-eletronico-do-cnj-pje-abriga-15-7-milhoesde-acoes. Acesso em abril de 2018. 
$\mathrm{Na}$ linha dos estudos realizados pelo Oxford Martin Programme on Technology, somente $0,5 \%$ da força de trabalho norte-americana encontra-se empregada em indústrias que não existiam na virada do século, um percentual significativamente menor do que os $8 \%$ de postos de trabalhos derivados das indústrias criadas durante a década de 1980 e dos 4,5\% criados durante a década de 1990 (SCHWAB, 2016, p. 44).

Tal estudo é acompanhado por um censo econômico realizado nos Estados Unidos que demonstra que as inovaçóes em tecnologias da informação e outras disruptivas tendem a elevar a produtividade por meio da substituição de trabalhadores, sem, contudo, criarem produtos que demandem mais trabalho para sua produção (SCHWAB, 2016, p. 44). Essa constatação empírica parece ir ao encontro da previsão de John Maynard Keynes de que a descoberta de meios para racionalizar o uso do trabalho ultrapassaria o ritmo de descoberta de novos usos para a força de trabalho economizada (SCHWAB, 2016, p. 41).

A se basear pelo atual cenário de avanço alcançado pelas legaltechs, notadamente aquelas que prestam serviços finalísticos relacionados à prática jurídica, e pelo ritmo exponencial de desenvolvimento da inteligência artificial, pode-se inferir que alguns serviços jurídicos já se encontram e outros, em pouco tempo, se encontrarão, ao menos em parte, sujeitos ao risco de substituição por máquinas.

Aliás, esse, aparentemente, é o ponto nevrálgico da discussão acerca dos efeitos da quarta revoluçáo industrial na dinâmica do trabalho jurídico: entender em que medida a evoluçáo tecnológica pode por em risco a demanda direta por advogados.

Por óbvio é muito difícil traçar qualquer prognóstico para o que vai de fato acontecer, mas nos parece certa que algumas carreiras relacionadas à área jurídica, tenham alta propensão à automação.

Toda essa indefinição quanto ao futuro e ao rumo da tecnologia geram apreensão em parte daqueles que se veem potencialmente afetados. À medida em que os avanços tecnológicos se integram à orbita da dinâmica jurídica, muitos profissionais da área, relutantes à aceitação das inovações tecnológicas, tendem a se posicionar de forma contrária a elas, criticando vorazmente a substituiçáo de plataformas e métodos.

Assim como países em desvantagens competitivas tendem a se valer de regras protecionistas para salvaguardarem seu mercado local, alguns profissionais da área do direito, receosos com as transformaçōes promovidas pelo evolucionismo tecnológico, não as aceitam, buscando, em última análise, a perpetuação do status quo.

No entanto, tal medida apenas beneficiará temporariamente os atuais "perdedores", conforme assinalado por Luigi Zingales (2015, p. 125). Realizando uma crítica à política protecionista de alguns Estados e à estratégia de retardo à incorporaçáo das inovaçóes tecnológicas, Zingales argumenta que tais medidas não trazem benefícios aos envolvidos, à exceção daqueles que se julgam prejudicados pelo avanço tecnológico. Nesse sentido, arremata o autor: 
Trata-se de uma estratégia consagrada pelo tempo. Quando a locomotiva a vapor foi inventada, os donos de diligências fizeram lobby para exigir que todos os trens fossem precedidos por um cavaleiro agitando uma bandeira por "questôes de segurança". Embora a medida não tenha alterado o futuro dos trens, ela retardou sua adoção, sem beneficiar ninguém além dos donos das diligências. (ZINGALES, 2015, p. 125)

Argumenta-se ainda que existe uma tendência natural à idealização de algumas profissóes classificadas como "moribundas", nos termos:

Existe uma tendência natural de idealizar profissōes moribundas - há um século eram os agricultores, hoje são os livreiros. No entanto, essa compaixão é uma maneira de expressar nostalgia por antigas formas de viver, um sentimento que desaparece conforme morrem as pessoas que viveram dessa maneira. Os leitores americanos, por exemplo, sentem compaixáo diante do desaparecimento do livreiro, mas nem se importam com as bancas de jornais especializadas. Assim os leitores tinham um relacionamento pessoal com o dono da banca, muitas vezes a primeira pessoa a lhes dizer bom-dia pela manhã - e se queixam do desparecimento das bancas à medida que os jornais on-line se tornam mais comuns. Na próxima geração, os livreiros estarão tão fora de moda nos Estados Unidos quanto os jornaleiros ou diligências." (ZINGALES, 2015, p. 125).

Evidentemente não se está, com tal alusão, a cogitar a iminência do completo esvaimento da atuação dos profissionais da área do direito, sobretudo dos advogados, mas tão somente a se criticar o apego a tradiçóes em virtude de um sentimento nostálgico associado ao receio do novo desconhecido.

No panorama dos processos judiciais eletrônicos, v.g., ainda há resistência à sua aplicação por parte de alguns usuários e até mesmo por parte dos servidores, sobretudo dos mais antigos, conforme apurado pelo Conselho Nacional de Justiça ${ }^{27}$.

Alguns especialistas da área de tecnologia afirmam que se trata de um caminho sem volta e estimam que a inteligência artificial será incorporada em quase todas as atualizaçóes de software até o ano de $2020^{28}$. Atualmente, ela já faz parte da dinâmica de inúmeras atividades profissionais cotidianas, a exemplo da análise de estimativas de indenização por seguradoras, de entrevistas de emprego, de condutas em relaçóes de venda, e de outras mais nas quais a inteligência artificial possa auxiliar no reconhecimento de padrôes e na transformação de dados não estruturados em estruturados, passíveis da aplicação de soluções automáticas.

Portanto, mais relevante do que conjecturar o futuro que nos é reservado, importa saber se tais impactos negativos relacionados ao redimensionamento do mercado de trabalho em decorrência dos avanços tecnológicos são contornáveis e de que modo é possível atingir tal propósito contemporizador.

Desenvolver, no plano acadêmico e no campo produtivo, uma postura mais integrada às inovaçóes tecnológicas, pode se revelar de grande auxílio nessa tarefa. A

27 Conforme sumário executivo produzido pelo CNJ.

28 GRAVA, Wilson. Inteligência Artificial: sem medo de abraçar o novo. Disponível em: https://www.ab2l.org.br/ inteligencia-artificial-sem-medo-de-abracar-o-novo. Acesso em abril de 2018. 
preparação da força de trabalho, por meio do desenvolvimento de novos modelos de ensino, se fará igualmente necessária (SCHWAB, 2016, p. 46).

A migração para profissões que prestigiem habilidades sociais e criativas, sobretudo a tomada de decisóes em ambientes de incerteza e o desenvolvimento de novas ideias, poderá representar uma saída para eventual cenário de remodelamento do mercado de trabalho decorrente náo só dos efeitos do avanço tecnológico, como também de pressões demográficas, de mudanças geopolíticas ou de novas normas sociais e culturais (SCHWAB, 2016, p. 51).

\section{Conclusáo}

Como apontado por autores relacionados ao longo deste trabalho, a quarta revolução industrial tem desencadeado transformaçóes significativas e disruptivas em vários setores e ocupaçóes. Um futuro hiperconectado e digital tem sido delineado por meio de projetos de aplicaçóes realistas, imediatas e mediatas (SCHWAB, 2016, p. 33).

No ambiente jurídico não é diferente. Os efeitos da quarta revolução industrial têm se feito presentes de forma crescentemente intensa na dinâmica do trabalho jurídico. A rápida expansão do número de legaltechs nacional e internacionalmente demonstra isso.

Ferramentas jurídicas de diversos níveis de interação não só auxiliam a realização de tarefas mecânicas e rotineiras, como também empregam nova feição à prática jurídica, inclusive no âmbito da relaçáo advogado e cliente, por meio da automatização, via softwares, de tarefas que, embora envolvendo baixa demanda cognitiva, eram até então exclusivas de advogados.

Conquanto as tentativas de futurologia se afigurem uma árdua e imprecisa missão, a compreensão do real impacto das novas e vindouras tecnologias no ambiente jurídico seria possível por meio da aferição e da avaliação pontual de como e em que exata medida cada uma das novidades apresentadas ou em desenvolvimento pelas legaltechs impactariam o mercado de trabalho dos profissionais da área do direito.

Em que pese essa parcial rejeição à aplicação e difusão de algumas inovações tecnológicas em certas áreas de atuação, inclusive no universo jurídico, a tendência é de que o processo evolucionário digital prossiga em expansão.

Por ora, enquanto náo realizado tal estudo minucioso e planificador, cabe ao intitulado "advogado 2.0" buscar se aperfeiçoar por meio de novas especializaçóes que, cada vez mais, demandem sua estrutura cognitiva, visando quiçá a uma reinvenção de seu modelo de atuação, para o fim de, em última análise, afastar o risco de automatização de suas competências, se náo totalmente, ao menos em parte. 


\section{Referências}

ASSOCIAÇÃO BRASILEIRA DE LAWTCHS E LEGALTECHS. Disponível em https://www.ab2l.org.br. Acesso em abril/2018.

AURUM. Disponível em https://www.aurum.com.br. Acesso em abril/2018.

CHA, Ariana Eunjung. Watson's next feat? Taking on câncer? The Washingtion Post, 27.06.2015. apud SCHWAB, Klaus. A Quarta Revolução Industrial; tradução: Daniel Moreira Miranda. - São Paulo: Edipro, 2016.

COHN, J. (2013 February 20). The robot will see you now. The Atlantic apud FREY, CB; OSBORNE, M., 2013. The Future of Employment: How suceptible are Jobs to computerization?, Op. cit.

COMO REGISTRAR. Disponível em https://www.comoregistrar.com.br. Acesso em abril de 2018.

COWORKING. Disponível em https://coworkingbrasil.org. Acesso em abril de 2018.

DIGESTO. Disponível em https://www.digesto.com.br. Acesso em abril de 2018.

EBERHARD, Birgit; et al. Smart work: The transformation of the labour market due to the fourth industrial revolution (I4.0). International Journal of Business \& Economic Sciences Applied Research. 10, 3, 47-66, Sept. 2017. ISSN: 24080098.

ESCAVADOR. Disponível em https://www.escavador.com. Acesso em abril de 2018.

FREY, C. B.; OSBORNE, M. A., 2013. The Future of Employment: How suceptible are Jobs to computerization?, Oxford University, Disponível em http://www. oxfordmartin.ox.ac.uk/downloads/academic/The_Future_of_Employment.pdf. Acesso em abril de 2018.

GETJUS. Disponível em https://www.getjus.com.br. Acesso em abril de 2018.

GRAVA, Wilson. Inteligência Artificial: sem medo de abraçar o novo. Disponível em: https://www.ab2l.org.br/inteligencia-artificial-sem-medo-de-abracar-o-novo. Acesso em abril de 2018.

GREENE, T. 9 technologies that could cut demand for lawyers, lower legal fees. CIO (13284045). 1, Feb. 9, 2016. ISSN: 13284045.

HWANG, Jennie S. The Fourth Industrial Revolution (Industry 4.0): Intelligent Manufacturing, SMT: Surface Mount Technology. Jul/2016, Vol. 31, Issue 7.

ITKOS. Disponível em http://www.itkos.com.br. Acesso em abril de 2018. 
JESUTHASAN, Ravin. People \& Strategy. Summer/2017, Vol. 40, Issue 3.

JOTA. Disponível em https://www.jota.info. Acesso em abril de 2018.

JURÍDICO CERTO. Disponível em https://juridicocerto.com. Acesso em abril de 2018.

JURIDOC. Disponível em https://www.juridoc.com.br. Acesso em abril de 2018.

JURIMETRIC. Disponível em http://www.jurimetric.com.br. Acesso em abril de 2018.

JUSBRASIL. Disponível em https://www.jusbrasil.com.br. Acesso em abril de 2018.

JUSTIÇA PESQUISA, POLÍTICAS PÚBLICAS DO PODER JUDICIÁRIO: Uma análise quantitativa e qualitativa do impacto da implantação do processo judicial eletrônico (PJe) na produtividade dos Tribunais. Disponível em http://www.cnj.jus.br/ files/conteudo/arquivo/2018/02/8fca1c5a0d1bac23a1d549c6f590cfce.pdf. Acesso em abril de 2018.

JUSTTO. Disponível em https://justto.com.br. Acesso em abril de 2018.

KEYNES, John Maynard. Economic Possibilities for our Grandclhildren, Essays in Persuasion, Harcourt Brace, 1931 apud SCHWAB, Klaus. A Quarta Revolução Industrial; Op. cit.

KURIER TECNOLOGIA. Disponível em http://kuriertecnologia.com.br/kurier-baixa. Acesso em abril de 2018.

LISTA DE LEGALTECHS DA UNIVERSIDADE DE STANFORD. Disponível em https://techindex.law.stanford.edu. Acesso em abril de 2018.

LOOPLEX. Disponível em http://www.looplex.com.br. Acesso em abril de 2018.

LUMINANCE. Disponível em https://www.luminance.com. Acesso em abril de 2018.

MCKINSEY, 2011, Wettbewerbsfaktor: Fachkräfte, Disponível em https://www. mckinsey.de/files/fachkraefte.pdf. Acessado em abril de 2018.

PROCESSOS ELETRÔNICOS. Disponível em http://www.cnj.jus.br/noticias/ cnj/85273-processo-eletronico-do-cnj-pje-abriga-15-7-milhoes-de-acoes. Acesso em abril de 2018 .

RADAR DE EMPRESAS ASSOCIADAS DA AB2L. Disponível em https://www.ab2l. org.br/radar. Acesso em abril de 2018.

ROSS INTELLIGENCE. Disponível em https://rossintelligence.com. Acesso em abril de 2018. 
ROTH, Armin. Einführung und Umsetzung von Industrie 4.0: Springer Gabler Verlag, 2016, apud EBERHARD, B; et al. Smart work: The transformation of the labour market due to the fourth industrial revolution (I4.0). International Journal of Business \& Economic Sciences Applied Research. 10, 3, 47-66, sept. 2017.

SCHWAB, Klaus. A Quarta Revolução Industrial; tradução: Daniel Moreira Miranda. - São Paulo: Edipro, 2016.

SEM PROCESSO. Disponível em https://www.semprocesso.com.br. Acesso em abril de 2018.

SEMANTIX. Disponível em http://www.semantix.com.br/semantix-aijus. Acesso em abril de 2018. 